\title{
A topology of residents' based on preferences for sustainable riparian settlement in Palembang, Indonesia
}

\author{
Maya Fitri $^{1,2}$, Sugeng Triyadi ${ }^{2}$ and Ismet B Harun ${ }^{2}$ \\ ${ }^{1}$ Architecture Department, Universitas Sriwijaya, 30662 Ogan Ilir, Indonesia \\ ${ }^{2}$ School of Architecture, Planning, and Policy Development, Institut Teknologi Bandung (ITB), 40132 Bandung, Indonesia
}

\begin{abstract}
The riparian function as an ecosystem service is very important. However, town planning with the sustainable of ecological riparian approach is often in conflict with public interest. Planner needs to harmonize planning with community preference. Several studies show that conjoint analysis is capable of capturing public opinion as part of town planning. In this paper, in addition to residential preference research, a topology of resident profiles was also identified. This study demonstrates that sample size can break the overall average results into particular group characteristics. The analyses are composed through two-step approach. First, cluster analysis to categorize residents as their preference settlements and conjoint analysis to know the ideal settlement to each group. There are 150 respondents in a slum settlements of Musi River in Palembang, Indonesia. The cluster analysis identifies four respondent groups and all of them prefer house building as the very important attributes rather than residential environment attributes.
\end{abstract}

\section{The principle of sustainable development in urban riparian}

Riparian has an important function as a transition area to maintain a balance between two ecosystems: water and land. It is a wetland located in floodplains that directly affected by the river waters tidal and the surface flow occurs in this area [1]. Riparian has an ecosystem service to improve water quality [2], control the natural water cycle [3], and maintain diverse aquatic habitat [4]. In addition, the riparian landscape presents unique ecological character of the city [5] and it reflects the culture and characteristics of waterfront city society [6].

The quality of ecology and community's culture coexists. The loss of riparian water culture threatens the riparian environment and, this ecological damage also degrades the quality of community life [7]. The concept of sustainable development was developed to promote sustainable living in response to an economic and social pressures created by demands on the nature of human society. The balance of it is important to protect, enhance, or restore ecosystems. It should be assessed across the wide range of riparian ecosystem services to deliver tangible and quantifiable value of societal interests [8]. Therefore, the consideration of human preferences and behaviors is an important component of the science behind sustainable planning [9].

Palembang is a city that has low, flat topography and hundreds of rivers. The surface water flow spreads along floodplain forming wetlands area along the riverbanks. The city culture is formed in a unique ecosystem composed by harmonizing water and daily community activities with the riparian landscape. However, currently this riparian ecosystem has begun to disappear. The main problem is the rapid increase of new housing area built in the riparian. The reduction of natural riparian degrades the ability of ecosystem service for city's urban live [10].

The studied settlement attributes can be divided into two components, i.e. building and environment. The only building component is residential type. The sustainable development needs to decrease building mass in the riparian built-up area to enlarge natural green space area. The building foundation in riparian should use the open for daylighting such as piling, piers, floating. The building should raise public awareness on city landscape with riparian architecture character. The next attribute is green buffer area. It is residential distance from the river edge. Buffer area provides natural space along streamside and preserves wetland natural spaces. The third attribute is riverside construction. Ideally, riparian edges should remain without flow and tidal blockage for floodplain area. This option provides the conservation of riparian ecosystem service but it conflicts with the needs of communities to be free from flooding. The fourth attribute is accessibility. Public access will promote the significance of a riparian ecosystem as an important character element of urban landscape [11]. The last attribute is riverside open space. Riparian zones perform a range of functions with economic and social value to people. Riparian buffer area has potential space for urban activities or ecological conservation. 
Table 1 List of attributes and their levels

\begin{tabular}{|c|c|}
\hline Attributes & Level attributes \\
\hline Residential type & $\begin{array}{l}\text { 1. Floating house } \\
\text { 2. Stilt row house } \\
\text { 3. Flats }\end{array}$ \\
\hline Distance to river edge. & $\begin{array}{ll}\text { 1. } & 0-10 \mathrm{~m} \\
\text { 2. } & 10-20 \mathrm{~m} \\
\text { 3. } & 20-30 \mathrm{~m} \\
\text { 4. } & >30 \mathrm{~m}\end{array}$ \\
\hline Riverside construction & $\begin{array}{l}\text { 1. Natural floodplain } \\
\text { 2. Polder } \\
\text { 3. Waterfront platform }\end{array}$ \\
\hline Accessibility & $\begin{array}{l}\text { 1. Boat dock } \\
\text { 2. Promenade }\end{array}$ \\
\hline Open space topology & $\begin{array}{l}\text { 1. Open green area } \\
\text { 2. Riparian park with trees } \\
\text { 3. Public playground field }\end{array}$ \\
\hline
\end{tabular}

This study addresses a better understanding of people preference of sustainable development residential profiles in riparian. The paper combines the use of cluster analysis in segmenting resident and a conjoint analysis to reveal their housing preference.

\section{Methodology}

\subsection{The conjoint analysis}

The conjoint analysis provides a robust method to understand the problem of multi attribute nature. The trade-offs involved several interactive variables in value changes of natural resources and environment [12]. In the conjoint survey, respondent chose residence like selecting housing brochures in property market. The conjoint model forces respondents to consider trade-offs among desirable and undesirable measures for the attributes rather than consider the importance of each attribute separately. The use of trade-off provides the important insight of type attributes residential that might motivate individuals to accept a planning of development [13].

The conjoint analysis method is one of the techniques to understand people behavioral intentions in housing preference. The residential and its environment have characteristics that can be seen as a choice of attributes that stimulates the cognition and behavior of a person ${ }^{14)}$. The attributes is measured by category and function usefulness that contains allegations part-worth or also called utility function. The conjoint analysis observes the part-worth utility of each level of the attributes that have the significance value in influencing decisions of a person's preference. The attributes value is different for each person. The more important the value the greater attention to it will be. Analyses such as regression and logit are usually used to determine the effect of utility. The procedure used in this study is the method of regression with dummy variables.

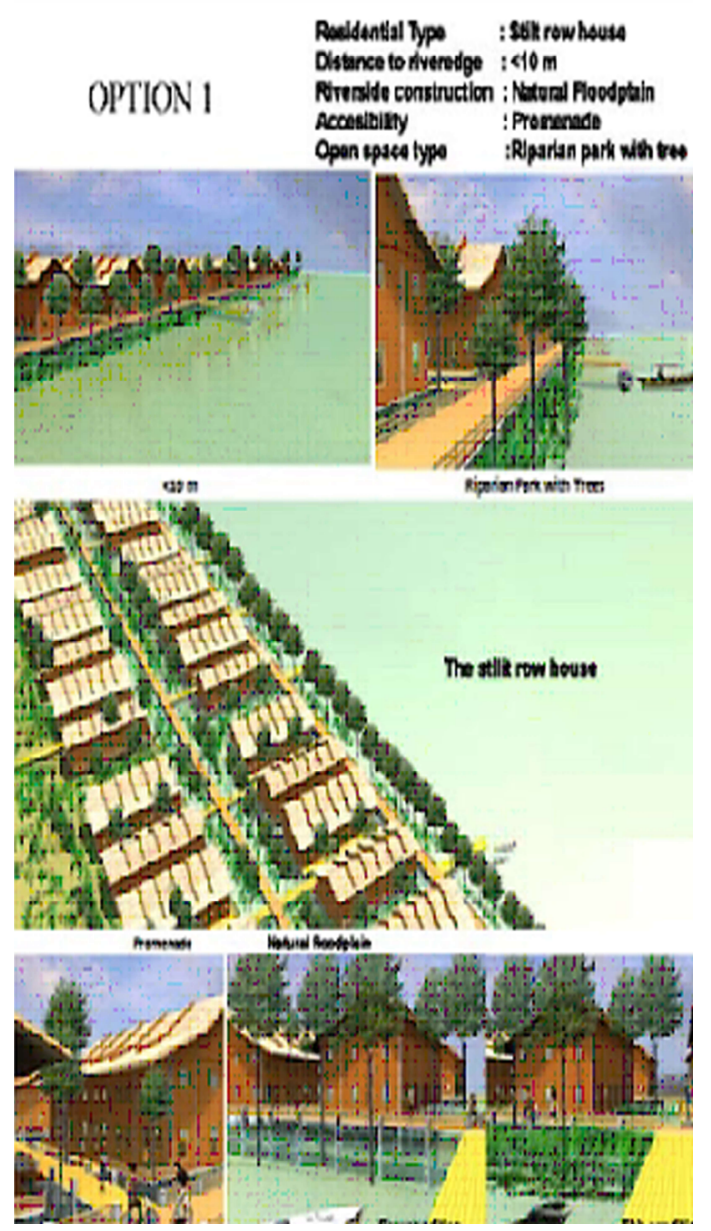

Fig. 1. An example of a residential profile set in conjoint rating question

This study uses part-worth utilities or coefficients of each respondent's utility function for segmenting respondents' preferences by means of clustering techniques. This approach focus on better representing heterogeneity in people preferences. Cluster analysis separates objects into several groups based on different characteristics among those groups. This analysis formed a group with homogeneous character among group members or similar to possessing character with as small variation as possible.

\subsection{Design of residential profiles}

The survey consists of five important attributes about water environment in residential area. These attributes were reselected by in-depth field observation and pretested survey among 35 arbitrarily selected respondents. Those five attributes were used in the study and each attribute was assigned two to four levels (see Table 1). Full-factorial experiments generate data with five 
attributes and fifteen levels is $3 \times 3 \times 3 \times 2 \times 4=216$ based on all possible combinations of attribute levels.

That large number is impractical for surveys because subjects' cognitive and time had limitations. The conjoint survey can use orthogonal fraction factorial experimental design to reduce the alternatives. It minimizes orthogonality, the occurrences of any two levels of different attributes that are uncorrelated, and minimize overlap cases where attribute levels do not vary within a choice set.

An iterative computer algorithm produces an efficient design. The orthogonal fraction factorial experiment created sixteen alternative profiles. It was presented on simple rating choice cards. It is also ilustrated with visual graphic with virtual reality experiment for better measurement.

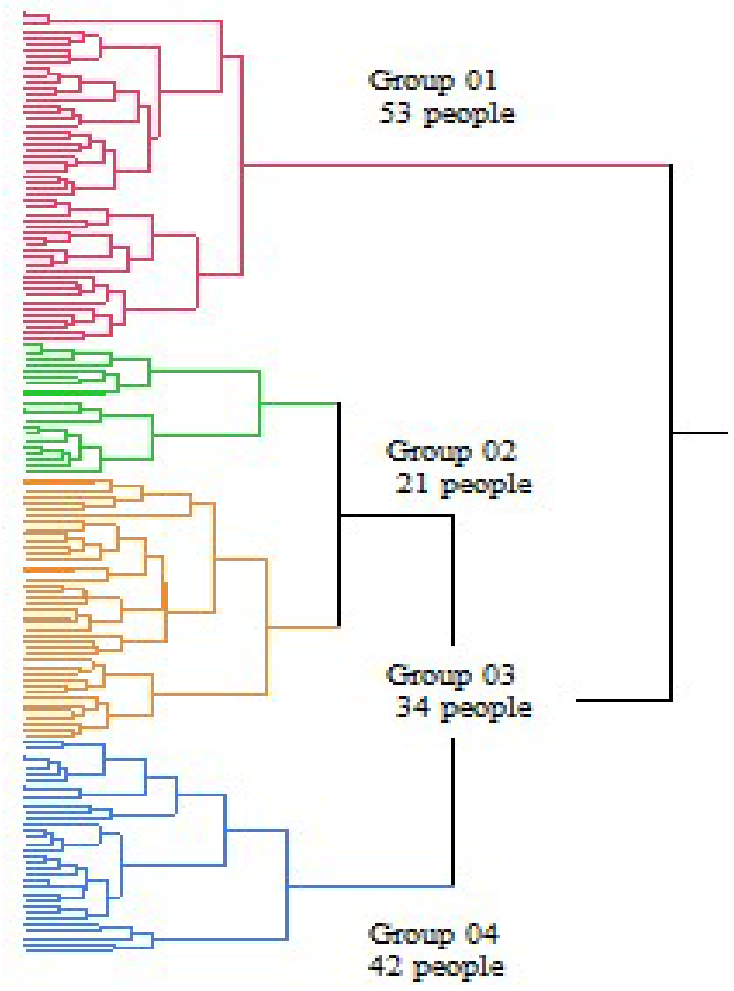

Fig. 2. Cluster analysis

\subsection{Survey administration}

The respondents chosen were those whose houses are within 250 meters from river edge. There were 150 samples. They were couples and individuals who were adult and eligible to make decision about the house. Each respondent answers a questionnaire within thirty minutes, including instructive information.

A trained surveyor conducted a door-to-door interview. They explained the content of sixteen profiles card one at a time and asked respondents to rate it. The rating scale is one to ten. It is numerical preference indicator in the continuous data.

\section{Results and discussion}

\subsection{Respondent clusters based on preference}

The analysis result divides respondents into four groups based on similarity on their preferences. This analysis uses clustering with ward method. In this method the distance between two clusters is the ANOVA sum of squares between two clusters for all variables. This method is used to combine small amounts of clusters (Milligan 1980 in [15].

\subsection{Conjoint analysis to each group}

\subsubsection{Residential mass}

The relative importance of residential type indicates this attribute receives a large portion of preference consideration. The value is more than half of all. The first cluster is about $55 \%$, while the second and the third clusters are $64.4 \%$ and $64.1 \%$, respectively. The importance of attribute for the fourth group exceeds others groups. Their focus in preference is almost entirely for residential type. It shows that they less care about environmental of riparian residential $(79.3 \%)$.

All groups have the same preference for the most attractive option. They all like stilts row house. Their preferences are different for the most undesirable residential type. The first cluster prefers floating house to flats.

\subsubsection{Distance to river edge}

The first group consider this attribute quite important. They put it as the second important attribute with 15,8 $\%$ attention to it. The first, second, and third groups are similar in this attribute preference. They consider twenty-one to thirty meters as the most ideal distance. These groups clearly dislike distance of more than thirty meters, except the the third. The third don't like most below ten meters. The fourth group preference analysis obtains different result. This cluster chose eleven to twenty as the best option, but same preference for the least option. This group also dislike residential distance that is too far from river edge $(>30 \mathrm{~m})$.

\subsubsection{Riverside Construction}

Riverside construction is an attribute associated with the tidal conditions of riparian, flood conditions, and convenience river access. The ecosystem approach requires constructions that do not block natural tidal. For people living in riparian residential area, this attribute usually get special attention. The first dan second groups agree that polder is a proper option for their needs. But, the third and fourth groups have different opinion. They like waterfront flatform. It improves the quality of residential environment by 
Table 2 Conjoint Analysis to Each Cluster

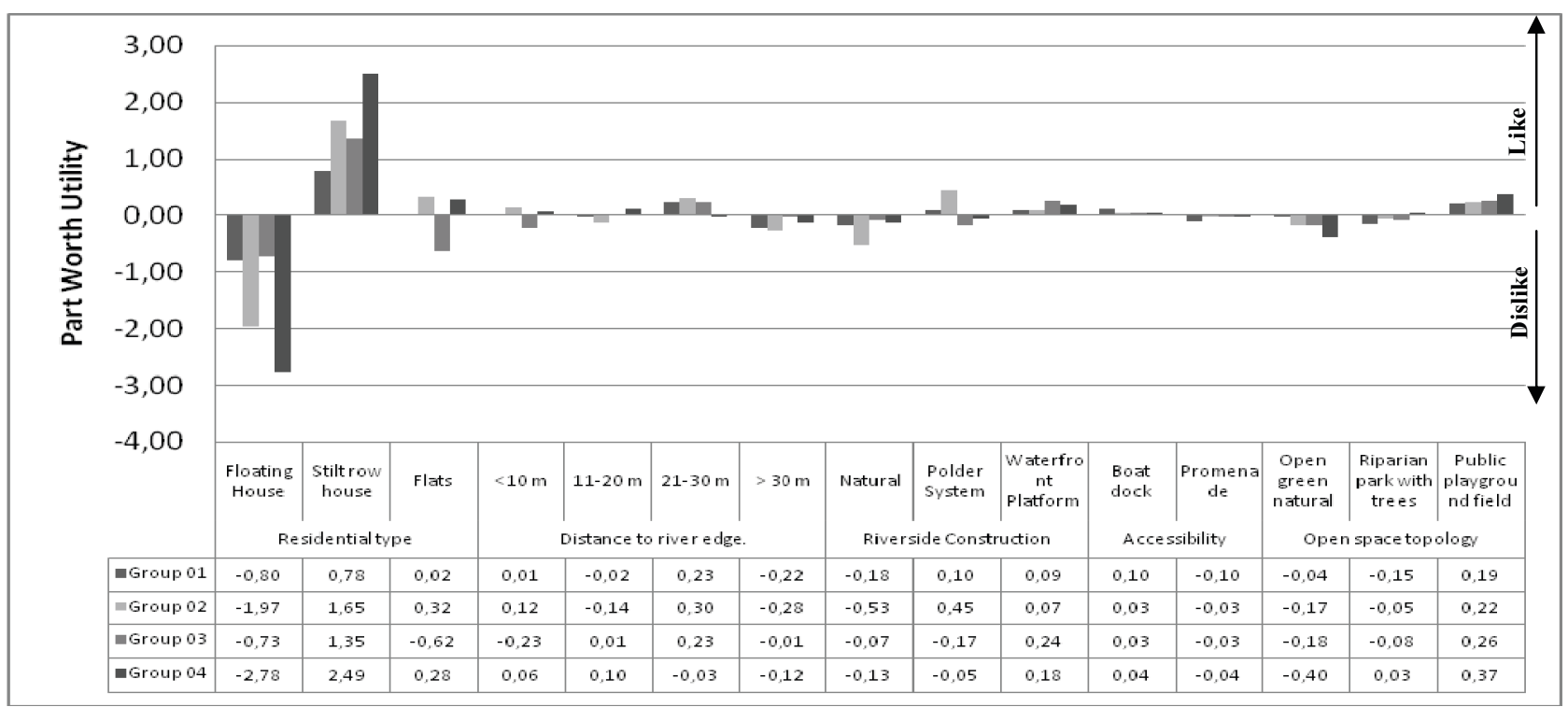

allocating a flood free open space. Three groups most dislike natural floodplain. This option does not protect.residence from flooding. Unlike the others, the third group chose a polder system $(-0.17)$ as the least preferred

\subsubsection{Open space topology}

The third and the fourth groups put this attribute as second priority after residential type, while the first group put it in the third position. It is not much different with the second group opinion. They give it as the fourth important attribute position and just give $6.9 \%$ attention.

All groups most like publik playground. The part-worth utility of this option is quite significant $(0.19,0.22,0.26$ and 0.37). Open green area is the most unattractive option for the three groups except the third group, while the only the second group that most don't like riparian park wit tree.

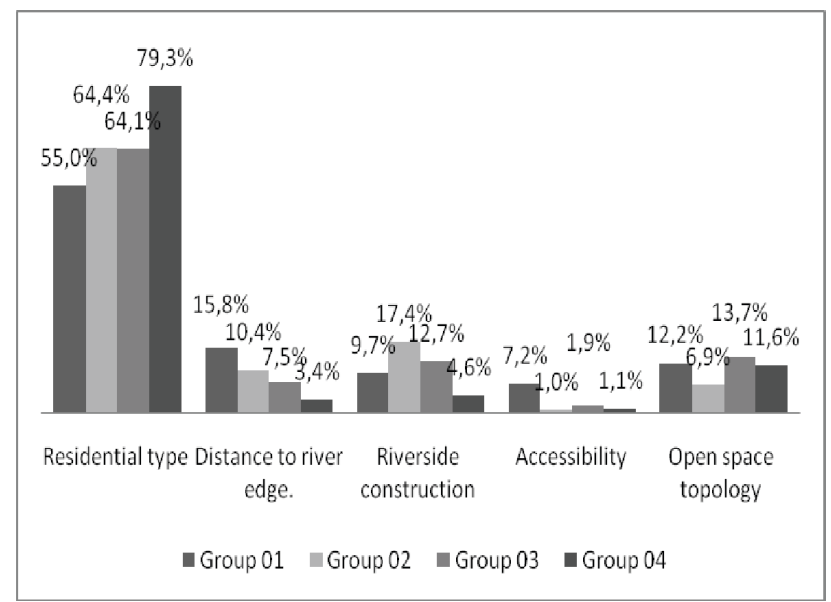

Fig. 3. Attribute importance for each group

\subsubsection{Accessibility}

Almost all groups do not concern with this attribute, except the first group. This group give this attribute with $7.2 \%$ value. Nevertheless, all groups tend to choose boat dock than promenade.

\section{Conclusions}

Town planners need to know the preferences of the residents to get a success planning. This study explains the importance of better understanding the people's preferences. In contrast to summarizing preferences into one set of attribute importance values and part-worth of level attribute utilities, clustering explores the differences among respondent that represents a resident segment. This approach is provided by multivariate analysis to get a topology of respondent. It does not focus on an easily preferences interpretable like the aggregation of preferences of all individuals within a region. It does not reveal all the information necessary for town planner. The opposing viewpoints can polarize all interpretation because it cancels out each other. Because of that, the preferences should be assessed separately for all relevant user groups.

\section{References}

1. Mitsch WJ, Gosselink JG. Wetlands. Fifth edition ed., John Wiley and Sons, Inc, Hoboken, NJ, (2015).

2. Fletcher TD, Vietz G, Walsh CJ. Prog. Phys. Geogr., 38, 543-555 (2014).

3. Spits J, Needham B, Smits T, Brinkhof T.. Nat. Cult., 5, (2010).

4. Meador MR, Goldstein RM. Water Physicochemistry, Riparian Condition, and Fish Community Structure. Environ. Manage., 31, 504-517 (2003).

5. Liao Q. Fuse. Mod. Appl. Sci., 5, (2011). 
6. Echols SP, Nassar HF. URBAN Des. Int., 11, 203-212 (2006).

7. Davenport MA, Bridges CA, Mangun JC, Carver AD, Williard KWJ, Jones EO. Environ. Manage., 45, 711722 (2010).

8. Everard M, Moggridge HL. Urban Ecosyst., 15, 293 314 (2012).

9. Scott M, Bullock C, Foley K. Town Plan. Rev., 84, 337370 (2013).

10. Burton ML, Samuelson LJ. Plant Ecol., 195, 99-115 (2008).
11. Qiu Z, Prato T, Boehm G. J. Am. Water Resour. Assoc., 42, 1583-1596 (2006).

12. Adamowicz W, Louviere J, Swait J. NOAA-Natl. Ocean. Athmospheric Adm. Wash. USA, (1998).

13. Alriksson S, Öberg T. Environ. Sci. Pollut. Res., 15, 244-257 (2008).

14. Molin EJ., Oppewal H, Harry J.P Timmermans. J. Hous. Built Environ., 16, 267-284 (2001).

15. JMP, A Business Unit of SAS. SAS Institute Inc., North Carolina 27513., (2007) 